\title{
Monoclonal antibody JC1: New reagent for studying cell proliferation
}

\author{
M C Garrido, J L Cordell, M H G Becker, G Key, J Gerdes, M Jones, K C Gatter, \\ DY Mason
}

\begin{abstract}
Aim: To characterise a newly developed mouse monoclonal antibody JC1 which recognises a nuclear antigen present in proliferating cells in normal tissues and neoplastic lesions, and which is absent in resting cells.
\end{abstract}

Methods: The methodology was established using a representative range of frozen sections from normal tissues and from certain tumours which were immunostained with antibodies Ki67 and JC1. The molecular weight of the antigen recognised by JC1 was obtained by western blot analysis and this was compared with that of Ki67. IM-9 cell lysates containing Ki67 derived plasmids were also tested with JC1 antibody.

Results: Biochemical investigation indicated that the antigen recognised by JC1 gives two molecular weight bands of 212 and 123 kilodaltons, which is distinct from the well characterised anti-proliferation monoclonal antibody Ki67 (395-345 kilodaltons). In addition recombinant Ki67 protein is not recognised by JC1. Immunohistological reactivity was seen in areas known to contain numerous proliferating cells such as lymphoid germinal centres, splenic white matter, cortical thymocytes and undifferentiated spermatogonia. In tumours many cells from adenocarcinomas, oat cell carcinomas, squamous cell carcinomas of lung, and seminomas were labelled by JC1 with a distribution and proportion similar to that seen with Ki67. In normal tissues the only apparent difference was in testis where JC1 stained a considerably greater number of cells than $\mathrm{Ki67}$. In all cases studied the new antibody showed nuclear reactivity only. JC1 did not show any cytoplasmic crossreactivity with squamous cells as is frequently seen with Ki67.

Conclusion: Antibody JC1, which recognises a nuclear antigen present in proliferating cells, should provide a useful adjunct to Ki67 as a marker of proliferation especially in those cases such as squamous cell carcinomas where a Ki67 index cannot be determined.

(F Clin Pathol 1992;45:860-865)

The rate at which a tumour proliferates has long been considered to indicate its clinical course. ${ }^{1-4}$ Histopathologists have therefore sought means of determining this as an adjunct to diagnosis. The development of monoclonal antibodies $^{5-10}$ recognising antigens present in cells during proliferation has brought this possibility within the realm of a general diagnostic laboratory.

The monoclonal antibody $\mathrm{Ki67}$ is perhaps the best known of such reagents and has been widely used to detect proliferating cells. ${ }^{10}$ There are now several studies which indicate a correlation between tumour proliferation rate as assessed by $\mathrm{Ki} 67$ immunoreactivity and clinical outcome. ${ }^{11-14}$ However, Ki67 has a well reported crossreaction with some epithelial cells, particularly of squamous type. This can lead to strong cytoplasmic reactivity making the determination of proliferation related staining impossible to define. This has led to the elimination of cases from experimental study, and, more importantly, will not allow some individual cases to be assessed in diagnostic practice. ${ }^{15-16}$

Here we report the production of a new mouse monoclonal antibody (designated JC1) that is similar to $\mathrm{Ki} 67$ in that it seems to recognise selectively nuclei in proliferating cells. However, it differs from the latter antibody in showing little or no cytoplasmic labelling in squamous or other cell types. In addition, it does not react with the same antigen as $\mathrm{Ki67}$, thus providing an independent assessment of tumour proliferation which might be valuable in clinical practice when individual cases are being evaluated.

\section{Methods}

A representative range of normal tissues was available from the frozen tissue bank stored at $-70^{\circ} \mathrm{C}$ in the Nuffield Department of Pathology, John Radcliffe Hospital. Samples of lung cancer (10 squamous cell, seven adenocarcinomas, and three oat cell carcinomas) and seminoma (10 cases) were obtained from the same source.

Immunostaining with both monoclonal antibodies $\mathrm{Ki} 67$ and JC1 was performed using a three stage immunoperoxidase technique as other studies had shown that, unlike Ki67, JC1 did not perform satisfactorily with the APAAP immunoalkaline phosphatase method. The percentage of tumour cells positive for $\mathrm{Ki} 67$ and $\mathrm{JCl}$ was established by counting 500 tumour cells from separate sections in each case. 
PREPARATION OF RECOMBINANT PARTS OF THE KI67 ANTIGEN

Construction of plasmids: Nucleotides 1-1002 of the $\mathrm{Ki} 67 \mathrm{cDNA}^{17}$ were cloned between the $E c o$ $R 1$ and Pst 1 sites of the $p A X 4 a+$ vector $^{18}$ (Medac, Hamburg, Germany). The resulting plasmid was designated pAX X2/1 and was transformed into $E$ coli JM $109 .^{19}$ A 100 base pair fragment, including a 62 base pair repetitive element ${ }^{17}$ was ligated between the $E$ co $R 1$ and $B a m H 1$ sites of the $p E V$-vrf vectors ${ }^{20}$ in all reading frames. The resulting plasmids were designated $p E V$-vrf $1 / B 3, p E V$-vrf 2/B3, $p E V$ vrf $3 / B 3$ and transformed into $E$ coli RR1. ${ }^{21}$

Preparation of bacterial cell lysates: An overnight culture of $E$ coli JM109 containing $p A X X 2 / 1$ was diluted to an $O D_{550}$ of 0.3 , grown to an $\mathrm{OD}_{550}$ of 1.0 , and induced with $1 \mathrm{mM}$ isopropylthio- $\beta$-galactoside (IPTG), according to Markmeyer et al. ${ }^{18}$ After an additional incubation for two and a half hours at $30^{\circ} \mathrm{C}$, bacteria were harvested by centrifugation, washed once in phosphate buffered saline (PBS), resuspended in 1 in 20 volume of PBS, and stored at $-20^{\circ} \mathrm{C}$ until further use. $E$ coli RR1 harbouring $p E V$-vrf $1-3 / B 3$ plasmids were cultured at $37^{\circ} \mathrm{C}$ in $\mathrm{M} 9$ medium $^{22}$ supplemented with $40 \mu \mathrm{g} / \mathrm{ml}$ ampicillin, $0.5 \%$ glucose, and casamino acids, respectively, until they reached an $\mathrm{OD}_{550}$ of $0 \cdot 8$. Bacteria were then harvested and lysates were prepared for sodium dodecyl sulphate-polyacrylamide gel electrophoresis (SDS-PAGE) and western blots, as described below.

IM-9 (multiple myeloma cell line, ATCC No CCL 159) was cultured under standard conditions in RPMI 1640 medium (Gibco, Berlin, Germany), supplemented with antibiotics and $10 \%$ fetal calf serum.

PREPARATION OF IM-9 CELL LYSATES

IM-9 cell line cells $\left(3 \times 10^{7}\right)$ were harvested by centrifugation ( 10 minutes at $400 \times g$ ) and suspended in $250 \mu \mathrm{l}$ PBS containing $1 \mathrm{mM}$ phenylmethylsulfonyl-fluoride (PMSF). The cell suspension was snap frozen with liquid nitrogen and homogenised in a mortar cooled in liquid nitrogen. The resulting powder was suspended in $300 \mu \mathrm{l}$ double concentrated Laemmli-SDS-PAGE sample buffer ${ }^{23}$ containing $100 \mathrm{mM}$ DTT, boiled for five minutes in a water bath, and briefly sonified to destroy contaminating DNA. Samples were then subjected to SDS-PAGE.

SDS-PAGE

SDS-PAGE was performed according to the method of Laemmli. ${ }^{23}$ IM-9 cell lysates were run on $5 \%$ separation gels, with $3 \%$ stacking gels. Electrophoresis of the two fusion proteins was performed on 7.5 and $12.5 \%$ separation gels, respectively. Molecular weight markers were obtained from Pharmacia/LKB (Freiburg, Germany) and Sigma (Munich, Germany).

\section{IMMUNOBLOTTING}

Proteins were transferred to nitrocellulose membranes (BA 85, Schleicher \& Schuell,
Dassel, Germany) using the western blot technique. $^{24}$ IM-9 cell lysates were blotted overnight at $4^{\circ} \mathrm{C}$ and $50 \mathrm{~mA}$ in a BIO-RAD blotting device (BIO-RAD, Munich, Germany); the fusion proteins were transferred in a Biometra (Gottingen, Germany) semi-dry blotting apparatus (two hours at $150 \mathrm{~mA}$ ). Unoccupied protein binding sites of the nitrocellulose were blocked by incubation for one hour with $1 \%$ bovine serum albumin or gelatine in TRIS-buffered saline (TBS). After one hour of incubation with primary antibody and thorough washing with TBS, the bound antibody was targeted with goat anti-mouse alkaline phosphatase conjugate, diluted 1 in 10000 in blocking solution. The phosphatase activity was visualised using nitro blue tetrazolium (NBT) and 5-bromo-4-chloro-3-indolyl phosphate (BCIP) as substrates. ${ }^{25}$

\section{Results}

CHARACTERISATION OF THE JC1 ANTIBODY AND ANTIGEN

Biochemical characterisation of antibody $¥ C 1$

Western blot analysis of IM-9 cell lysates showed that there were two bands with molecular weights of 212 and 123 kilodaltons (fig 1A). These are quite clearly different from the bands seen with Ki67 on the same cell lysate preparation (fig 1A). Additional evidence that $\mathrm{JCl}$ antigen is distinct from $\mathrm{Ki} 67$ antigen is shown by western blotting with both antibodies of protein preparations prepared from the transfection of Ki67 c DNA plasmids into $E$ coli. In no case were any of the resultant fusion proteins recognised by JC1 (figs $1 \mathrm{~B}$ and C).

\section{Normal human tissues}

In human tonsils (figs $2 \mathrm{~A}$ and $\mathrm{B}$ ) antibody JC1 stained the nuclei of nearly all centroblasts in the dark zone, a varying number of centrocytes in the light zone of germinal centres, and the nuclei of only a small number of follicular mantle lymphocytes. This pattern of staining was virtually identical with that seen in parallel sections labelled by antibody $\mathrm{Ki67}$. In the overlying squamous epithelium of the tonsil (figs $3 \mathrm{~A}$ and $\mathrm{B}$ ) there was a distinct difference in the staining pattern seen with $\mathrm{JCl}$ and $\mathrm{Ki} 67$. With Ki67 there is a strong cytoplasmic reactivity with the epithelial cells especially of the basal and intermediate layers. This makes it difficult to appreciate the nuclear labelling. However, Ki67, in general, seems to label nuclei preferentially in the basal layer. JC1 has no cytoplasmic crossreactivity so that nuclear staining is clearly seen as being localised almost exclusively in the intermediate layer, with only an occasional positive nucleus being observed in the basal layer.

In two other lymphoid organs, thymus (figs $4 A$ and $B$ ) and spleen, both antibodies gave a similar staining pattern in the areas known to contain the most proliferating cells-that is, the cortex of the thymus and the white matter in the spleen.

In specimens of five different testes, a sharp difference was observed between $\mathrm{Ki} 67$ and 

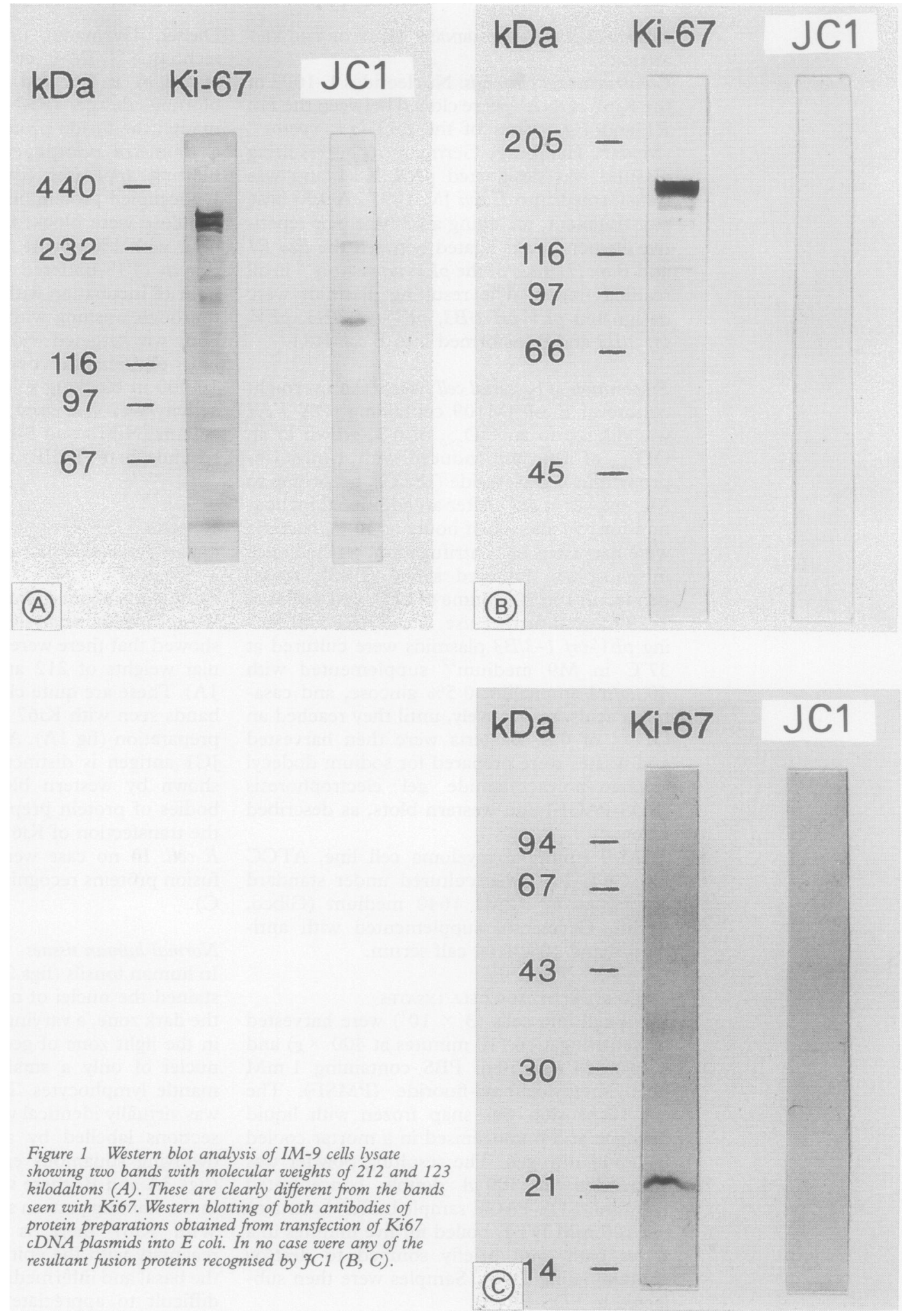

Figure 1 Western blot analysis of IM-9 cells lysate

showing two bands with molecular weights of 212 and 123 kilodaltons $(A)$. These are clearly different from the bands seen with Ki67. Western blotting of both antibodies of protein preparations obtained from transfection of Ki67 cDNA plasmids into $E$ coli. In no case were any of the resultant fusion proteins recognised by $\mathcal{F C 1}(B, C)$.

JC1. Ki67 generally stains only a small number of undifferentiated spermatogonia located in the basal layer of the seminiferous tubule (fig 5A). JC1 labels a much larger number of undifferentiated spermatogonia extending towards the lumen with additional staining of some spermatocytes $\mathrm{S} 1$ and spermatides $\mathrm{S} 3$ (fig 5B). Neither of the two antibodies stained mature spermatozoa or Leydig cells.

In other normal tissue, comprising liver, kidney, pancreas, thyroid, prostate, lung and brain, only an occasional nucleus was labelled by either antibody and no difference was seen in their distribution or number. In proliferating

normal tissues like gut or bone marrow, no difference in quantity or quality of staining between the two antibodies was noted. Table 1 summarises the results.

\section{Malignant lung and testicular tumours}

The number of labelled nuclei per 500 cells counted for each tumour type is shown in table 2. There was no significant difference between the two antibodies in the adenocarcinomas and oat cell carcinomas of the lung (figs 7A and B). In five of the cases of squamous cell carcinomas of the lung there was also no difference in staining between Ki67 and JC1. However, in 


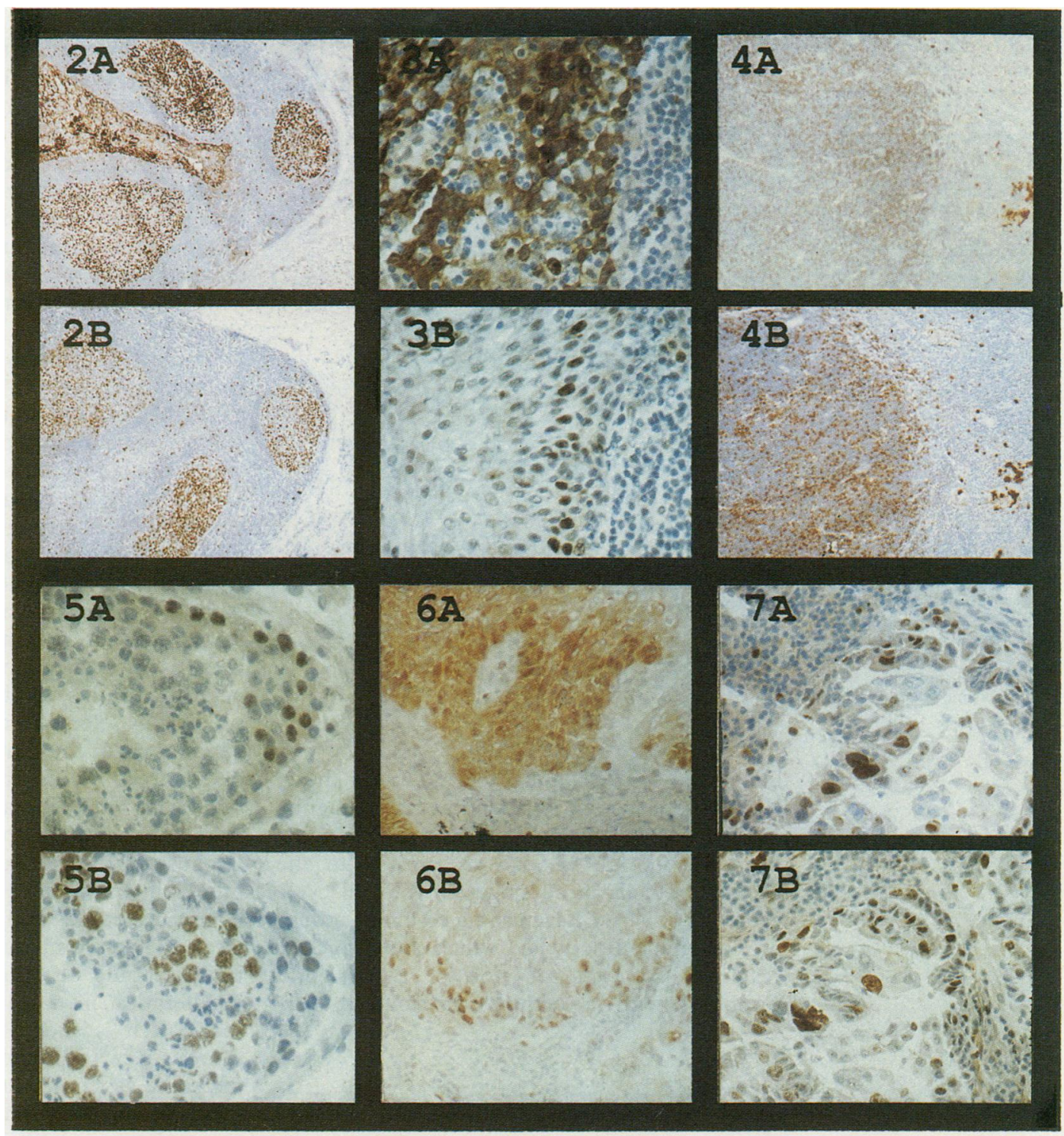

Figures $2 A, B$ Immunostaining of human tonsil with both Ki67 $(A)$ and $¥ C 1(B)$, respectively. Lymphoid follicules show virtually identical pattern of staining by both antibodies in parallel sections, with strong staining of the germinal ientres and a few positive cells from the mantle zone. (Three stage immunoperoxidase technique).

Figures $3 A, B$ Reactivity of the overlying squamous epithelium of tonsil: Note the difference in the staining pattern between Ki67 (A) and $¥ C 1$ (B). Ki67 showing a strong cytoplasmic cross reactivity of the epithelial cells from the basal and intermediate layers making the nuclear labelling difficult to appreciate. Occasional nuclei from the basal layer are stained by Ki67. In contrast, $\mathcal{F} C 1$ shows no cytoplasmic cross-reactivity but clear nuclear staining is localised in the intermediate layer with only an occasional nucleus being observed in the basal layer. (Three stage immunoperoxidase technique).

Figures $4 A, B$ Immunostaining of the human thymus: both antibodies, Ki67 (A) and $¥ C 1$ (B) show strong positive labelling of cortical thymocytes. (Three stage immunoperoxidase technique).

Figures $5 A, B$ Immunostaining of human testis: Ki67 (A) shows labelling of a small number of undifferentiated spermatogonia from the basal layer of the seminiferous tubule contrasting with $¥ C 1$ (B) which shows labelling of a larger number of undifferentiated spermatogonia extending towards the lumen of the seminferous tubule. (Three stage immunoperoxidase technique).

Figures $6 A, B$ Reactivity of squamous cell carcinoma of the lung: Ki67 shows pronounced background staining $(A)$ which obscures the nuclear labelling. A parallel section from the same case stained with $\mathcal{F C 1}(B)$ shows reactivity confined to the nuclei. (Three stage immunoperoxidase technique).

Figures $7 A, B$ Immunostaining of a typical case of adenocarcinoma of the lung: both antibodies show almost identical patterns of staining with Ki67 $(A)$ and $\Im C 1(B)$.

the remaining five cases it was only possible to achieve a count of nuclei with JC1 because the level of background staining with $\mathrm{Ki} 67$ was so high. These cases had been selected from previous studies of $\mathrm{Ki} 67$ labelling in lung cancer where they had been eliminated from inclusion due to this effect (figs $6 \mathrm{~A}$ and $\mathrm{B}$ ).

In view of the difference noted betwen $\mathrm{Ki} 67$ and JC1 on normal testis 10 cases of seminoma were selected for study. There was a consistent difference, with a higher number of cells being labelled by JC1 (table 2). However, this difference was not significant $(p>0.134)$ and there was no evidence of the striking difference in distribution of the staining by the two antibodies as was seen in normal testis.

\section{Discussion}

Several monoclonal antibodies that identify a variety of cell cycle related antigens have recently been described as markers of pro- 
Table 1 Staining characteristics of Ki67 compared with $¥ C 1$ in sections from normal human tissues

\begin{tabular}{|c|c|c|}
\hline & Ki67 & $F C 1$ \\
\hline $\begin{array}{l}\text { Squamous epithelium overlying tonsils } \\
\text { Basal layer } \\
\text { Intermediate } \\
\text { Granular layer }\end{array}$ & $\begin{array}{l}++++\star \\
+\star \\
-\end{array}$ & $\begin{array}{l}+1- \\
+++ \\
++\end{array}$ \\
\hline $\begin{array}{l}\text { Tonsils: } \\
\text { Germinal centres }\end{array}$ & +++ & +++ \\
\hline $\begin{array}{l}\text { Testis: } \\
\text { Undifferentiated spermatogonia } \\
\text { Differentiated }\end{array}$ & $\stackrel{+}{-}$ & $\begin{array}{l}+++ \\
++\end{array}$ \\
\hline $\begin{array}{l}\text { Skin: } \\
\text { Basal layer } \\
\text { Intermediate } \\
\text { Granular layer }\end{array}$ & $\begin{array}{l}++++^{\star} \\
+\star \\
-\end{array}$ & $\begin{array}{l}+1- \\
++ \\
++\end{array}$ \\
\hline $\begin{array}{l}\text { Kidney } \\
\text { Liver } \\
\text { Brain } \\
\text { Lung } \\
\text { Thyroid } \\
\text { Pancreas } \\
\text { Prostate } \\
\text { Bone marrow and gut }\end{array}$ & $\begin{array}{l}- \\
- \\
- \\
- \\
\overline{-} \\
\overline{-} \\
\text { All prolifer }\end{array}$ & $\begin{array}{l}- \\
- \\
- \\
- \\
- \\
- \\
- \\
\text { artments }\end{array}$ \\
\hline
\end{tabular}

Key: $+++>80 \%$ of cells show nuclear staining.

$+++50-80 \%$ of cells show nuclear staining.

$++10-50 \%$ of cells show nuclear staining.

$+<10 \%$ of cells show nuclear staining.

$+/-$ Only occasional cells show nuclear staining.

- Negative staining.

*Cytoplasmic staining also seen. similar to that seen with $\mathrm{Ki} 67,{ }^{26}$ for example in tonsil and thymus, bone marrow and gut. However, we know from the molecular weight of the JC1 antigen that it differs from Ki67. This is reflected in two important observations made in the current study. The first is that JC1 does not cross-react with a cytoplasmic antigen in squamous epithelium. The second is that the distribution of nuclear staining is not identical with Ki67 in all normal tissues such as testis and skin.

The lack of cytoplasmic staining with JC1 on squamous epithelium may be of considerable value in studies of squamous tumours. Several studies have reported this effect with $\mathrm{Ki} 67$ which has led to the elimination of some cases from evaluation; examples include cervical cancers ${ }^{1629}$ and lung carcinomas. ${ }^{15}$ Furthermore, this effect has also been noted in breast carcinoma $^{30}$ and haematological diseases. ${ }^{31}$ Although these were not specifically addressed in the present preliminary survey with $\mathrm{JC1}$, there is no reason to suppose that it would occur with this antibody. In this study we specifically selected a number of squamous cell carcinomas of the lung that we had previously been forced to eliminate from our investigations with $\mathrm{Ki67}$. In each case JC1 gave a clear nuclear staining without any cross-reaction. Because JC1 correlated well with Ki67 in the other squamous cell carcinomas and in the adenocarcinomas and oat cell carcinomas, it is clear that a combination of these two antibodies should be valuable in future studies of proliferation in these tumour types. Furthermore, if it is shown that a measurement of tumour growth fraction is useful in determining some aspect of tumour behaviour, such as prognosis or drug sensitivity, it will be important to have an antibody such as JC1 for study of those cases which cannot be evaluated with Ki67 alone.

The second major difference from $\mathrm{Ki} 67$ concerned mainly the testis. JCl stained a larger and different number of undifferentiated spermatogonia than $\mathrm{Ki} 67$. The reason for this is unknown but must obviously reflect a distinction in the localisation of the two antigens in testis which is not detectable in most other tissues. Interestingly, this did not seem to affect the measurement of proliferating cells in the series of seminomas, a malignancy directly arising from seminiferous tubules. However, it emphasises that caution must always be observed in comparing results from antibodies recognising different antigens and that future studies would do well to incorporate both antibodies or at least another independent measure of proliferation.

This work was supported by the Leukaemia Research Fund.

1 Chauvel P, Courdi A, Gioanni J, et al. The labelling index: a prognostic factor in head and neck carcinoma. Radiother Oncol 1989;14:231-7.

2 Costa A, Banadonna G, Villa E, Valagussa P, Silvestrini R. Labelling index as a prognostic marker in non-Hodgkin's lymphoma. INCI 1981;66:1-5.

3 Meyer JS. Cell kinetic measurements of human tumors. Hum Pathol 1982;13:874-7.

4 Strang P, Eklund G, Stendahl U, Frankendal B. S-phase rate as a predictor of early recurrences of carcinoma of the uterine cervix. Anticancer Res 1987;7:807-10. 
5 Smetana K, Gyorkey F, Chan P-K, Tan EM, Busch H. Proliferating cell nuclear antigen (PCNA) and human malignant nucleolar antigens (HMTNA) in nucleoli of human haematological malignancies. Blut 1983;46: 133-41.

6 Celis JE, Bravo R, Larsen PM, Fey SJ. Cyclin: a nuclear protein whose level correlates directly with the pro-
liferative state of normal as well as transformed cells. Leuk Res $1984 ; 8: 143-57$.

7 Garcia RL, Coltrera MD, Gown AM. Analysis of proliferative grade using anti PCNA-cyclin monoclonal antibodies in fixed, embedded tissues. Comparison with flow cytometric analysis. Am f Pathol 1989;134:733-9.

8 Galang P, Degraef C. Cyclin/PCNA immunostaining as an alternative to tritiated thymidine pulse labelling for marking $S$ phase cells in paraffin sections from animal and human tissues. Cell Tissue Kinet 1989;22:383-92.

9 Hall PA, Levision DA, Woods AL, et al. Proliferating Cell Nuclear Antigen (PCNA) Immunolocalization in paraffin sections: An index of cell proliferation with evidence of deregulated expression in some neoplasms. F Pathol deregulated expressi

10 Brown DC, Gatter KC. Monoclonal antibody Ki67: its use in histopathology. Histopathology 1990;17:489-503.

11 Hall PA, Richards MA, Gregory WM, d'Ardenne AJ, Lister $\mathrm{TA}$, Stanfield AG. The prognostic value of $\mathrm{Ki} 67$ immunostaining in non-Hodgkin's lymphoma. $f$ Pathol 1988;154:223-5.

12 Gerdes J, Stein H, Pileri S, et al. Prognostic relevance of tumour cell growth fraction in malignant non-Hodgkin's lymphomas. Lancet 1988;ii:448-9.

13 Grogan TM, Lippman SM, Spier CM, et al. Independent prognostic significance of a nuclear proliferation antigen in diffuse large cell lymphomas as determined by the monoclonal antibody $\mathrm{Ki}-67$. Blood 1988;71:1157-60.

14 Schrape S, Jones DB, Wright DH. A comparison of three methods for the determination of the growth fraction in methods for the determination of the growth fraction in
non-Hodgkin's lymphoma. Br f Cancer 1987;55:283-6.

15 Gatter KC, Dunnill MS, Gerdes J, Stein H, Mason DY. New approach to assessing lung tumours in man. $f$ Clin Pathol 1986;39:590-3.

16 Brown DC, Cole D, Gatter KC, Mason DY. Carcinoma of the cervix uteri: An assessment of tumour proliferation using monoclonal antibody $\mathrm{Ki} 67$. Br $\mathcal{F}$ Cancer 1988; 57:178-81.

17 Gerdes J, Li L, Schluter C, et al. Immunobiochemical and molecular biologic characterization of the cell proliferation-associated nuclear antigen that is defined by monotion-associated nuclear antigen that is defined by mono-

18 Markmeyer P, Ruhlmann A, Englisch U, Cramer F. The pAX plasmids: new gene-fusion vectors for sequencing and expression of proteins in Escherichia coli. Gene 1990; 93:129-34

19 Yanish-Perron C, Vieira J, Messing J. Improved M13 phage cloning vectors and host strains: nucleotide sequences of the M13mp18 and pUC19 vectors. Gene 1985;33: 103-19.

20 Crowl R, Seamans C, Lomedico P, McAndrew S. Versatile expression vectors for high-level synthesis of cloned gene products in Escherichia coli. Gene 1985;38:31-8.

21 Bolivar F, Backmann K. Plasmids of Escherichia coli as cloning vectors. Methods Enzymol 1979;68:245-67.

22 Sambrook J, Fritsch EF, Maniatis T. Molecular cloning. In: $A$ laboratory manual, 2 nd ed. New York: Cold Spring Harbour, 1989:A3

23 Laemmli UK. Cleavage of structural proteins during the assembly of the head of bacteriophage T4. Nature 1970;227:680-5.

24 Towbin H, Staehelin T, Gordon J. Electrophoretical transfer of proteins from polyacrylamide gels to nitrocellulose sheets: procedure and some applications. Proc Natl Acad Sci USA 1979;76:4350-4.

25 Leary JJ, Brigati DJ, Ward DC. Rapid and sensitive colorimetric method for visualizing biotin-labeled DNA colorimetric method for visualizing biotin-labeled DNA
probes hybridized to DNA or RNA immobilized on probes hybridized to DNA or RNA immobilized on nitrocellulose:

26 Gerdes J, Schwab U, Lemke H, Stein H. Production of a mouse monoclonal antibody reactive with human nuclear antigen associated with cell proliferation. Int $\mathcal{f}$ Cancer 1983;31:13-20.

27 Ogata K, Kurki P, Celis JE, Nakamura RM, Tan EM. Monoclonal antibodies to a nuclear protein (PCNA cyclin) associated with DNA replication. Exp Cell Res 1987;168:476-86.

28 Gerdes J, Lemke $\mathrm{H}$, Baisch $\mathrm{H}$, Wacker $\mathrm{H}-\mathrm{H}$, Schwab U, Stein H. Cell cycle analysis of a cell-proliferation assoStein $\mathrm{H}$. Cell cycle analysis of a cell-proliferation associated human nuclear antigen defined by the mon

29 Guillaud P, du Manoir S, Segneurin D. Quantification and topographical description of Ki67 antibody labelling during cell cycle of normal fibroblastic (MRC-5) and mammary tumours cell lines (MCF-7). Anal Cell Pathol 1989;1:25-39.

30 Walker RA, Camplejohn RS. Comparison of Monoclonal antibody $\mathrm{Ki} 67$ reactivity with grade and DNA flow cytometry of breast carcinomas. $\mathrm{Br} 7$ Cancer 1988:57: 281-3.

31 Scott CS, Ramsden W, Limbert HJ, Master PS, Roberts BE. Membrane transferrin receptor (TfR) and nuclear proliferation associated $\mathrm{Ki}-67$ expression in hemopoietic malignancies. Leukemia 1988;2:438-42. 